\title{
The Morality of Suicide
}

\author{
Mohamed Nashnoush ${ }^{1}$ and Muneeza Sheikh ${ }^{2}$ \\ ${ }^{1}$ Dalhousie University \\ 2 University of Texas at Dallas \\ https://doi.org/10.15273/hpj.v1i1.10589
}

Warning: Please note that some readers may find the following content contained in this paper disturbing due to the sensitive nature of the topic discussed. Reader discretion is advised.

\begin{abstract}
The motivation behind attempting suicide ranges from egoistic to altruistic, with societal preconceptions varying significantly between the two. In this ethical review, moralist, relativist, and libertarian theories are utilized to explore the morality of suicide. The hedonistic act utilitarian theory, which assesses the righteousness of an action solely based on the amount of pleasure or displeasure it creates, is used to evaluate the morality of suicide. According to the beneficence principle, there is sometimes a moral justification for suicide to alleviate suffering. On the other hand, Mill's rule utilitarianism views actions by their effect on overall human happiness and directs us to perform actions that maximize utility. For some individuals, like those undergoing immense suffering, the right to painless suicide would maximize utility. Kantian theory focuses on an individual's duty to uphold honour, dignity, and rationality. Collectively, these three virtues set the foundation of Kantian deontology. Furthermore, the libertarian view emphasizes the inherent right of human beings to individual security, liberty, and property with minimum government intervention. Libertarians recognize that suicide can be a rational and reasonable response to intolerable suffering. The ethical theories have proven to be interdependent; together, they propel us toward a better understanding of the morality of suicide.
\end{abstract}




\section{The Morality of Suicide}

Suicide is the 14th leading cause of mortality in meritocratic societies, where an individual's failures are viewed as an irreconcilable existentialist verdict on one's soul (Frey, 1999). Suicide reminds us of the fragility of the human psyche and how self-inflicted psychological torment can lead humanity to the brink of self-destruction (Fisher et al., 2018). Although suicide is often deemed a taboo topic, it is vital to examine suicidal ideation to comprehend the underlying morality (Fisher et al., 2018). The motives behind suicide attempts can range from egoistic to altruistic (Singer, 2003). Egoistic suicide is characterized by a loss in social cohesion and possession of a cynical attitude, consistent with the facets of Western modernity (Szasz, 2002). Altruistic suicide is characterized as a benevolent type of suicide that involves self-sacrifice for the greater good of everyone else (Singer, 2003). The societal preconceived notions of the types of suicide vary dramatically (Beauchamp et al., 2007). For instance, altruistic suicide is often seen as heroic, while egoistic suicide is perceived as dishonourable because an individual refuses to partake in their duty of reciprocity to society (Singer, 2003).

Ethical sentiments toward suicide can be broadly classified as relativist, moralist, and libertarian (Ho, 2014; Szasz, 2002). The relativistic approach evaluates the cost-tobenefit ratio of suicide by accounting for the cultural, temporal, financial, and situational circumstances of the suicidal person under consideration. Whether suicide is deemed acceptable or not depends on the needs of the individual in the context of the situation (Ho, 2014). Rule and act utilitarianism best exemplify the relativistic ethical framework (Feldman, 2006). The central core of the moralist school of thought is the sanctity of life principle, according to which human life is of inherent value regardless of the quality of life lived (Brassington, 2006). Moralism supports the moral obligation to strive for the protection of life and the prevention of suicide. Moralists like Kant have a propensity for deontology, a school of thought that judges the morality of an action based on rules instead of its consequences, and condemn hedonistic egoism (Ho, 2014). The libertarian notions revolve around the indispensability of patient autonomy and non-interference of authority in personal matters (Ho, 2014; Szasz, 2002). Libertarians assert that suicide is the most fundamental right of being a human (Szasz, 2002). In this ethical analysis, the relativist, moralist, and libertarian theories are applied to explore the morality of suicide. The primary inference of this paper is that suicide is permissible only under extenuating circumstances, as supported by act utilitarianism, rule utilitarianism, Kantian deontology, and libertarian theory.

\section{Discussion}

\section{Relativist Theory: Act Utilitarianism}

The hedonistic act utilitarian theory applies the utility principle impartially to appraise the morality of suicide (Beauchamp et al., 2007; Feldman, 2006; Fisher et al., 2018). Act utilitarianism, as proposed by Bentham, judges the righteousness of an action by the net pleasure or displeasure it produces (Feldman, 2006). The quality of pleasure or displeasure can be ranked by considering the intensity, duration, certainty, fecundity, propinquity, and purity of the pleasure (Beauchamp et al., 2007; Feldman, 2006). Higher displeasures are not driven by our emotional impulses and involve a complex cognitive element (Fisher et al., 2018). In the context of suicide, we ought to resort to the beneficence principle, as there is no pleasure accompanying the act of suicide, but there are ways of curtailing the net displeasure (Fisher et al., 2018). The beneficence principle refers to doing good by reducing displeasure and pain (Feldman, 2006). In cases of suicide, where the net empirical displeasure is minimized, such suicide attempts could be justified (Feldman, 2006). A patient who is suicidal after a terminal illness diagnosis may view their future as bleak, so ending their life may seem like the only way to escape their anguish (Feldman, 2006). An egoistic suicide of that nature may be justified; 
however, if the individual has multiple dependents who rely upon them or if their suicide will breed profound feelings of bereavement in immediate family members and friends, their suicide may be impermissible (Beauchamp et al., 2007; Feldman, 2006; Fisher et al., 2018). Empirical, evidential support, as calculated by Bentham's felicific calculus, is required to determine the legitimacy of a suicide (Feldman, 2006). Higher levels of displeasure are reflected in rational, persistent, informed, and voluntary requests to end one's life (Beauchamp et al., 2007; Feldman, 2006). Moreover, a minimized negative impact on society, relatives, and friends all contribute to increasing the permissibility of suicide (Feldman, 2006). In this case, the utilitarian act theory appears to be moderate, holistic, contextual, and personalized.

An implication of act utilitarianism is that suicidality is not necessarily a symptom of mental illness, as obsolete psychiatric literature has had us believe (Beauchamp et al., 2007; Feldman, 2006). Although a significant number of suicide attempts are associated with mental illness, suicidality is by no means a direct sign of mental illness (Ho, 2014). It is important to avoid inculcated, social preconceived notions of suicide, as recourse to such stereotypes of suicide aggravates rather than ameliorates the suicidality of patients (Feldman, 2006). Suicide can be a rational, well-contemplated decision that an informed, psychologically stable individual pursues (Feldman, 2006; Ho, 2014).

The principles of act utilitarianism further suggest that suicidality in the mentally ill is unlikely justified, as a distorted moral agency cannot yield rational, informed, or voluntary decisions (Beauchamp et al., 2007; Feldman, 2006). Additionally, anomic suicides characterized by impulsivity and spontaneity lack a well-grounded basis and are often a significant loss to society, making them impermissible (Feldman, 2006).

\section{Relativist Theory: Rule Utilitarianism}

Mill's rule utilitarianism centres around the aggregate long-term consequences of actions by deriving general rules that apply universally (Fisher et al., 2018). An escape from needless and incurable suffering ought to be a viable option for eligible candidates who are motivated by higher displeasures and whose deaths present a limited impact on society, as this ultimately maximizes utility (Beauchamp et al., 2007; Feldman, 2006). A universal rule that allows individuals under extenuating circumstances to complete suicide does not pose any dangers if the appropriate safeguards are followed (Feldman, 2006). Mill's harm principle further substantiates the aforementioned point, as paternalistic restraint is an offence to an individual's liberty (Feldman, 2006; Ho, 2014). The harm principle argues that individuals should be permitted to pursue whatever they please if other citizens are not harmed (Beauchamp et al., 2007; Feldman, 2006). This principle reinforces rule utilitarianism in many regards and precludes repressive dogmas that are ultimately associated with less utility (Feldman, 2006).

\section{Moralist Theory: Religious Stance}

One of the most popular moralist viewpoints advocating for the preservation of life is the religious stance that claims that the mere act of suicide is an affront to God, as we may be encroaching upon God's province (Frey, 1999). Whether or not suicide is a violation of God's will is more of a theological argument than a moral argument (Szasz, 2002). Nonetheless, the argument does not hold, due to subjectivism in the interpretation of God's word (Frey, 1999; Szasz, 2002). Allowing someone to complete suicide is as rebellious as saving someone by performing CPR because, in both cases, we may be thwarting God's plan (Fisher et al., 2018; Frey, 1999). If suicide is an interruption of the natural laws, why is saving a life any less of a disturbance of nature?

Alternatively, one can argue that being saved by CPR was destined to happen and that the physician utilized the powers endowed rightly by God without being impious (Frey, 1999). By the same token, we ask why those same endowed capacities cannot be employed to end one's life. This logical incoherence and subjectivity around God's will renders the 
argument futile and unreliable when investigating the morality of suicide (Frey, 1999; Szasz, 2002).

Furthermore, the religious absolutist stance advocating for the sanctity of life principle is not well-founded and appears overly idealistic (Frey, 1999). The sanctity of life principle claims that life is of intrinsic worth, as it is a gift from God (Frey, 1999; Szasz, 2002). It claims that we have a debt of gratitude to pay, and repaying this debt comes in the form of doing good to others, which requires that we accept the gift of life that has been granted to us (Szasz, 2002). Taking one's life through suicide would be denying God's gift and would exhibit ingratitude (Frey, 1999). However, is life still considered a gift if it becomes unbearable and characterized by irreversible deterioration of health, complete dependency, and extreme anguish? We would no longer have the capacity to care for or benefit ourselves, let alone benefit society in such circumstances (Frey, 1999; Szasz, 2002). Moreover, we would not have the capability to repay the debt of gratitude as we are incapable of contributing to our community, and thus, our life serves no purpose (Frey, 1999). The sanctity of life principle appears to contradict itself when applied to terminally ill patients, and as such, we ought to resort to a more robust systematic moralist stance such as Kantian deontology.

\section{Moralist Theory: Kantian Deontology}

Kantian deontology is based on categorical imperatives, where moral duties are unconditional, dispassionate, and impartial (Beauchamp et al., 2007; Cholbi, 2015; Fisher et al., 2018). Moral duties are discoverable by reasoning, and moral credibility is solely determined by the moral will underlying an action. Formulations are central pillars to Kantian theory, guiding sentient beings in making rigorous moral appraisals (Beauchamp et al., 2007; Cholbi, 2015). A related formulation to the discussion of suicide is the respect of personhood formulation, which demands that every individual should be treated as an end in themselves and never merely as a means to an end (Budić, 2018). Many may argue that by completing suicide one opts to renounce their moral agency and thereby relinquishes their personhood by using themselves as a means to an end (Budić, 2018; Cholbi, 2015). Proponents of the anti-suicide stance also use the Kantian self-love principle to explain that suicide is contradictory to self-love and claim that the maxim of suicide can never be universalized without adverse results (Beauchamp et al., 2007; Budić, 2018; Cholbi, 2015). However, Kant's thoughts are more nuanced than critics infer. It is true that Kant generally perceives suicide as defective and as an unnatural way to confront reality, but he acknowledges that sometimes suicide is acceptable (Budić, 2018). Shallow motives behind suicide like unhappiness or despair are unjustifiable (Budić, 2018; Cholbi, 2015), but Kant regards suicide as an acceptable last resort when an individual loses the fundamental virtues that grant life value (Cholbi, 2015).

Kantian deontology revolves around three fundamental virtues that trump the need to preserve biological life (Budić, 2018; Cholbi, 2015). These three virtues are honour, dignity, and rationality (Budić, 2018). Collectively they allow us to pursue a moral existence and imbue us with an absolute moral worth (Beauchamp et al., 2007; Budić, 2018; Cholbi, 2015). A life devoid of such pivotal virtues is of no value (Cholbi, 2015). In the case of irreversible dementia, where patients gradually lose the ability to rationally think and remember, it is difficult to see value in their lives (Budić, 2018; Cholbi, 2015). Rationality gradually decays with the progression of dementia, and with it, dignity is lost as autonomy and self-esteem are unrealized (Cholbi, 2015; Fisher et al., 2018). Honour, which is a social construct, becomes unattainable when the patient is seen as a burden and fails to follow the social code of conduct (Cholbi, 2015). Such an instance where an individual is deprived of honour, dignity, and rationality exemplifies an individual losing their moral agency, while barely clinging onto their biological life (Budić, 2018). An advance directive issued by the patient at the onset of the terminal disease should be provided to ensure the decision is autonomous, informed, 
voluntary, and rational (Beauchamp et al., 2007; Cholbi, 2015). After all, autonomy is the basis of dignity, and by necessitating an advance directive we would ascertain the patient is treated as an end, satisfying the second formulation of Kantian deontology (Budić, 2018; Cholbi, 2015).

The maxim subject to universalization would be that any individual diagnosed with a terminal illness and either expected to be or currently deprived of honour, dignity, and rationality should have the right to undergo active euthanasia (Brassington, 2006). Such a maxim is unlikely to apply to individuals suffering from terminal morbidities who are content with their life, as satisfaction presupposes some variant of honour, dignity, and rationality (Brassington, 2006; Budić, 2018; Cholbi, 2015). The maxim can be universalized in a subset of the population that qualifies without any foreseeable dire ramifications (Brassington, 2006). There may be some practical limitations when applying this maxim, especially with regard to the administration and method of delivery.

\section{Libertarian Theory: Libertarianism}

The libertarian outlook has been adopted in nations where suicide has been decriminalized, where patient autonomy trumps the clinical duties of preserving life (Fisher et al., 2018; Szasz, 2002). Libertarians acknowledge that suicidality can be a rational and reasonable response to intolerable suffering (Szasz, 2002). The principles of individualism and individual liberty contradict the psychiatry practice of involuntary hospitalization, where psychiatrists coercively dominate a patient's life by chemical or physical restraints. Although hospitalization, constant monitoring, and environmental restriction can help in temporarily preventing the patient from completing suicide, these measures are by no means an optimal solution (Fisher et al., 2018; Szasz, 2002). In fact, such extensive measures promote regression and dependency, which opens more doors for oppressive and restrictive interventions (Szasz, 2002).
Libertarian theory treats patients as free agents capable of determining their beliefs and actions while minimizing state intervention. However, patients are often not free agents and are influenced by social and political factors, which obscure or gloss over their genuine needs (Fisher et al., 2018). The overreliance on the patient's judgments may lead us to prematurely euthanize individuals who would have been happier alive, and as such libertarian theory should be applied with caution while continuing to respect patient autonomy (Fisher et al., 2018; Szasz, 2002).

\section{Conclusion}

All the discussed ethical sentiments present a compelling account of the morality of suicide in the clinical context. The relativistic stance, as represented by act and rule utilitarianism, highlights how the permissibility of suicide is contingent upon a holistic and contextual moral appraisal. This is best exemplified in Bentham's act utilitarian theory, where the motives are ranked and ascribed points accordingly, while the societal effects are assessed based on impactfulness. Mill's stance reveals how proffering eligible candidates the right to die maximizes utility. On the other hand, the religious stance subsumed under the moralist outlook proves to be flawed due to the logical incoherence and the subjectivity present in the interpretation of God's will. In Kantian theory, the absence of the three keystone virtues leaves an individual without a moral agency and hence a life of no value as exemplified by the dementia case. The derived maxim proves to be universalizable, and respect of the patient's personhood arises in relying on an advance directive that an autonomous, informed, and rational patient formulates at the outset of the terminal morbidity. Lastly, the libertarian stance underlines how suicidality could be a rational response to suffering and how patient autonomy should be held as being of the utmost importance. The main deduction from this ethical review is that suicide could be a rational choice that is completely permissible under extenuating circumstances. 
The theories are interconnected, and an amalgamation of the principles of the deliberated theories certainly brings us a step closer to unravelling the morality of suicide. It also appears that as one theory emerges as inflexible and rigid, the other theories compensate, allowing us to develop a more overarching picture. The most fundamental example of this is how utilitarianism compensates for the absence of a consequentialist element in Kantian deontology. The inferences of this ethical analysis should only be accepted prima facie, as there may be other ethical principles unaccounted for here.

\section{References}

Beauchamp, T. L., Walters, L., Kahn, J. P., \& Mastroianni, A. C. (Eds.). (2007). Contemporary issues in bioethics (7th ed.). Wadsworth.

Brassington, I. (2006). Killing people: What Kant could have said about suicide and euthanasia but did not. Journal of Medical Ethics, 32(10), 571-574. https://doi.org/10.1136/jme.2005.015 420

Budić, M. (2018). Suicide, euthanasia and the duty to die. Filozofija i društvo, 29(1), 88-114. https://doi.org/10.2298/FID1801088B

Cholbi, M. (2015). Kant on euthanasia and the duty to die: Clearing the air. Journal of Medical Ethics, 41(8), 607-610. http://dx.doi.org/10.1136/medethics2013-101781

Feldman, D. B. (2006). Can suicide be ethical? A utilitarian perspective on the appropriateness of choosing to die. Death Studies, 30(6), 529-538. https://doi.org/10.1080/07481180600 742517

Fisher, J., Russell, J. S., Browne, A., \& Burkholder, L. (Eds.). (2018). Biomedical ethics: A Canadian focus (3rd ed.). Oxford University Press.

Frey, R. G. (1999). Hume on suicide. The Journal of Medicine and Philosophy, 24(4), 336351. https://doi.org/10.1076/jmep.24.4.336 .5982

Ho, A. O. (2014). Suicide: Rationality and responsibility for life. The Canadian Journal of Psychiatry, 59(3), 141-147. https://doi.org/10.1177\%2F07067437 1405900305

Singer, P. (2003). Voluntary euthanasia: A utilitarian perspective. Bioethics, 17(56), 526-541. https://doi.org/10.1111/14678519.00366

Szasz, T. (2002). Fatal freedom: The ethics and politics of suicide. Syracuse University Press. 